\title{
Recent developments and knowledge in pseudocereals including technological aspects
}

\author{
D. Bender and R. Schönlechner*
}

Department of Food Science and Technology, University of Natural Resources and Life Sciences Vienna, Muthgasse 18, 1190, Vienna, Austria

\section{REVIEW PAPER}

Received: June 18, 2021 • Accepted: July 2, 2021

Published online: July 20, 2021

(C) 2021 The Author(s)

\begin{abstract}
Amaranth, buckwheat, quinoa, and less known, canihua are the most important pseudocereals. Their high nutritional value is well recognized and they are increasingly used for the development of a wide range of starch-based foods, which has been fostered by intensified research data performed in recent years. In addition to health driven motivations, also environmental aspects like the ongoing climate change are an important stimulus to increase agricultural biodiversity again. As pseudocereals are botanically classified as dicotyledonous plants their chemical, physical and processing properties differ significantly from the monocotyledonous cereals. Most important factors that need to be addressed for processing is their smaller seed kernel size, their specific starch structure and granule architecture, their gluten-free protein, but also their dietary fibre and secondary plant metabolites composition. This review gives a condensed overview of the recent developments and gained knowledge with special attention to the technological and food processing aspects of these pseudocereals.
\end{abstract}

\section{KEYWORDS}

pseudocereals, amaranth, quinoa, canihua, buckwheat, processing properties

*Corresponding author. Tel.: +43 147654 75240. E-mail: regine.schoenlechner@boku.ac.at 


\section{INTRODUCTION}

\subsection{History and increased interest today}

Cereals play an important role for human nutrition and are a staple food in almost all parts of the world. Rice, maize and wheat are the three most produced cereal species, but there are several other cereal species like millet, sorghum, oat and barley, as well as the pseudocereals amaranth, quinoa, canihua and buckwheat.

Buckwheat was originally grown in Asia and Siberia and was then spread to India, Japan, and further to Europe and North America. Still the main production and consumption of buckwheat occurs in Russia, Ukraine, Belarus Estonia and China, today, but also in Europe and USA it is grown in significant amounts. Amaranth, quinoa and canihua are one of the oldest used crops, which have been traditionally used as staple foods in Latin American countries before the Spanish conquest. Many centuries thereafter their use has been neglected, due to various cultural and historical reasons, but in the mid-20th century these grains were "re-discovered" and their contribution of human nutrition was recognized again. Although for some decades they remained niche products, since about 10-20 years their production has begun to rise immensely. Drivers for this increased consumption have been their nutritional properties, but in particular the fact of being gluten-free grains. In particular quinoa has shifted from being a traditional grown grain to a globally traded commodity (FAO, 2013). Today, the use of alternative cereals is receiving increased attention, which can be related to several reasons. Generally, populations around the world increasingly care about health-related issues and also about their nutrition. Several trends like wholesome, healthy, natural, or minimally processed, and within cereals e.g. wholegrain, gluten-free, rich in dietary fibre or resistant starch, (s)low carb, or digestibility have arisen. Pseudocereals are well recognized grains in this respect today and they are well appreciated for their nutritional properties. In addition to such health driven motivations, also environmental aspects are of concern to the consumers; the ongoing climate change is an important stimulus for people to reconsider their nutritional behavior. Nutrition, or more specifically, its agricultural production has a major impact on climate change, but it also can be considered reversely: the effects of the climate change on agricultural production are becoming more evident in many regions world-wide. An increase in agricultural biodiversity might help to address some of these adverse aspects.

An increased use of pseudocereals for human nutrition induces the food producers to develop new and convenient food products, which requires not only know-how about the chemical composition of these raw materials, but also fundamental information about their physical and functional properties for processing. In the last couple decades research in this respect has produced a vast amount of new data and knowledge. This review aims to give a condensed overview of the recent developments and gained knowledge with special attention to the technological and food processing aspects of pseudocereals.

\subsection{Agricultural properties and seed morphology}

Under the term "pseudocereals" a group of dicotyledonous plants is summarized that produce starch-rich grains that can be used similarly to the monocotyledonous cereals, although they differ regarding their botanical classification. The most common pseudocereals are amaranth, quinoa and buckwheat. 
Buckwheat belongs to the genus Fagopyrum, which comprises 24 species. Among them, three buckwheat species have been the focus of investigation due to their traditional food and medicinal use. These include common buckwheat (Fagopyrum esculentum Moench), tartary buckwheat (Fagopyrum Tartaricum Gaertn.) and perennial buckwheat (Fagopyrum divobotrys D.Don), whereas the latter is mostly used in Chinese medicine. Each species differs in phenotype as well as nutritional and phytochemical composition (Jing et al., 2016). Buckwheat seeds have a triangular, pyramidal shape, which is a challenge for milling. Their thousand kernel weight (TKW) ranged from 17.6 to $25.9 \mathrm{~g}$ in 10 commercially available buckwheat seeds. The embryo is smaller than in amaranth and quinoa and is located within the kernel at the distal part (Kreft and Kreft, 2000). In terms of cultivation, buckwheat is not very demanding with regard to soil and water and can also be grown on poor soils.

The family amaranthus consists of many species, of which three are mainly used as grains: Amaranthus hypochondriacus L., Amaranthus cruentus L. and Amaranthus caudatus L. A. caudatus is the major species grown in the Andean countries, where it is usually called kiwicha. All grain amaranth plants produce small seeds, which can vary in its color. The TKW is very low with $0.69 \mathrm{~g}$ as determined by De Bock et al. (2021) for 8 different, commercially available amaranth seeds. The grains contain the episperm, consisting of a very thin layer of cellular tissue, the endosperm, the embryo, made up of protein-rich cotyledon, and the perisperm, where in contrast to true cereal, the starch is stored (Di Fabio and Parraga, 2017). The embryo surrounds the seed in form of a ring and can make up to $25 \%$ of the seed weight. Protein and fibre were negatively correlated with TKW, which suggests that the embryo portion is higher in amaranth with a low TKW, as proteins are mainly located in the seed embryo. Ash content was increased with TKW. As minerals and fat are also stored in the embryo, it is assumed that not the proportion but the composition of the embryo is to a large extent determinative for the TKW of amaranth (De Bock et al., 2021). Amaranth requires rather warm climate conditions and is quite adaptable to diverse environmental conditions, but it has to be considered that it is a short-day species. For future interest could be the fact that amaranth is a C4 plant, which is known to possess a more efficient photosynthesis pathway and requires less water in comparison to cereals, which are C3 plants. Also buckwheat and quinoa are C3 plants. With ongoing climate change amaranth might therefore serve as a suitable alternative for cereals that are less heat and drought tolerant.

Quinoa (Chenopodium quinoa Willd) and canihua (Chenopodium pallidicaule Aellen) are plants of the Chenopodiaceae family which are both important food crops in the Andean region. Quinoa includes around 250 species and 3,000 varieties conserved in germplasm banks (VegaGalvez et al., 2010). While today quinoa is well-known worldwide, canihua is still mainly used in the Andean region. Quinoa produces small round seeds, around $2 \mathrm{~mm}$, that can vary from white, yellow, purple, brown or black. TKW values ranged around 2.19-4.04 g in 7 commercially available quinoa seeds. The TKW of quinoa increased with a decrease in the ash content (De Bock et al., 2021). Seeds of canihua are smaller, around $1 \mathrm{~mm}$, and usually brown. Also these two seeds possess a ring-embryo like amaranth and its starch is stored in the perisperm tissue. In terms of cultivation, quinoa is characterized by an excellent resistance towards drought, salinity, pests and diseases, and can therefore easily adapt to different environmental conditions. Compared to amaranth and buckwheat, quinoa is less frost sensitive, but it can tolerate cold climate conditions (Ranilla et al., 2009). 


\section{CHEMICAL AND NUTRITIONAL COMPOSITION}

\subsection{Carbohydrates, starch, dietary fibre}

Carbohydrates are the major components in pseudocereals, ranging from 48.5 to $77.0 \%$ in quinoa, $60-70 \%$ in canihua $63.1-70.0 \%$ in amaranth and $63.1-82.2 \% \mathrm{dm}$ in buckwheat (RepoCarrasco-Valencia et al., 2010; Martínez-Villaluenga et al., 2020). The main carbohydrate is present as starch, its content in amaranth ranges in average from 55 to $65 \%$, in quinoa from 52.2 to $72 \%$ (Kringel et al., 2020, De Bock et al., 2021), in canihua from 48 to 51\% (Repo-CarrascoValencia et al., 2010) and in buckwheat from 54.5 to 78\% (Martínez-Villaluenga et al., 2020, De Bock et al., 2021). Compared to true cereals the amounts are slightly lower. Simple carbohydrates are found as minor components, yet their quantities are higher in pseudocereals than in most cereals, in amaranth, quinoa and canihua at about 3-5\% (Pereira et al., 2019), and lower in buckwheat. The main monosaccharides and disaccharides are glucose, fructose, arabinose, xylose, and sucrose and maltose, respectively.

Starch structure and composition are important factors that influence its physicochemical properties and digestibility and, in this respect, pseudocereal starch is distinct to cereal starch. Amaranth, quinoa and canihua starch granules are among the smallest starch granules known, which are less than $3 \mu \mathrm{m}$ in quinoa, $0.5-1.5 \mu \mathrm{m}$ in canihua and only $0.3-2.5 \mu \mathrm{m}$ in amaranth (Srichuwong et al., 2017, Martínez-Villaluenga et al., 2020). In amaranth, the starch granules can be polygonal, lenticular, circular or elliptical, while in canihua they are usually polygonal and in quinoa they are rather irregular, ranging from polygonal to angular. Additionally, oblong aggregates $(10-20 \mu \mathrm{m})$ of several single starch granules can be found in quinoa (Srichuwong et al., 2017). In buckwheat, starch granules are mostly polygonal with sizes ranging from 2 to $15 \mathrm{~mm}$ and an average diameter of 6-7 $\mathrm{mm}$ (Zhu, 2016).

The ratio of the two polymers of starch, amylose and amylopectin are again differing in pseudocereals compared to cereals. Amylose, a rather linear and small polymer, is found in low amounts in amaranth (4.7-12.5\%) and quinoa (3.5-22\%) (Kringel et al., 2020) and slightly higher in canihua (11-20\%) (Repo-Carrasco-Valencia and Arana, 2017), they can thus be considered as waxy starches. In contrast, in buckwheat starch the amylose content is higher (18.3-47\% of total starch), usually even higher than found in cereals (Zhu, 2016; Repo-Carrasco-Valencia and Arana, 2017). Amylopectin is a highly branched glucan polymer, organized in cluster structures. The branch chain length and its distribution are major parameters within the starch polymer that affect the physicochemical properties and digestibility of starch. Srichuwong et al. (2017) found that quinoa and amaranth starches were characterized by a larger proportional amount of short chains with a degree of polymerization (DP) of 6-12 and a distinguished shoulder around DP 18-20. They mentioned that a relatively high ratio of shorter chains (around DP 6-12) might indicate inferior crystalline structures. In contrast, amylopectin in buckwheat was characterized by a high amount of extra-long unit chains (DP > 100), which is higher than that of cereal amylopectin (Zhu, 2016). This overall starch architecture and composition explain the high digestibility of amaranth and quinoa starch, they are both known to be rapidly hydrolyzed to glucose (90\%) in comparison to wheat (79.5\%). Major influences for this high enzyme susceptibility are the low amylose content, small granule size and less dense starch granules (Srichuwong and Jane, 2007). 
Cereals and pseudocereals are important sources for dietary fibre, which is associated with several health-beneficial effects. The amount of dietary fibre in pseudocereals is comparable to cereals, $7.0-26.5 \%$ in quinoa, $2.7-17.3 \%$ in amaranth and around $17.8 \%$ in buckwheat (Martínez-Villaluenga et al., 2020). In canihua the amount of dietary fibre depends on the presence of the outer seed coat (perigonium), thus it can be 12-25\% (Repo-Carrasco et al., 2003; Repo-Carrasco-Valencia et al., 2010). Canihua is often consumed in soups as whole grain including the perigonium. The major part is comprised by insoluble dietary fibre with $78-86 \%$, soluble dietary fibre ranges from 14 to $22 \%$ in amaranth, quinoa and buckwheat (MartínezVillaluenga et al., 2020), in canihua the content of soluble dietary fibre is lower at round 2-3\%. While the overall dietary fibre values are comparable between cereals and pseudocereals, significant variations can be seen in their composition, which can be explained by their botanical different classification. Cell walls in monocotyledonous cereals are of type II and are composed of a coarse network of cellulose fibrils, which are interlocked by glucurono-arabinoxylans (GAXs) and B-glucans that are embedded in a less dense protein matrix. Grasses are in general poor in pectin (Carpita and Gibeaut, 1993). In dicotyledonous plants like the pseudocereals, cell walls are of type I, which contain about equal amounts of cellulose and cross-linking xyloglucans (XyGs), with various minor amounts of arabinoxylans, glucomannans, and galacto-glucomannans. The cellulose-XyG framework of type I walls is embedded in a pectin matrix. The two major pectins are homogalacturonans and rhamnogalacturonan I (Carpita and Gibeaut, 1993). In pseudocereals, being dicots, pectins are therefore quantitatively dominant. Their soluble dietary fibre includes homogalacturonans and rhamnogalacturonan-I with arabinan sidechains (55-60\%), as well as highly branched xyloglucans (30\%) and cellulose in quinoa and in amaranth the composition is $40-60 \%$ xyloglucans and $34-55 \%$ arabinose-rich pectic polysaccharides (\% of soluble fibre fraction) (Lamothe et al., 2015).

\subsection{Proteins}

Pseudocereals are known to have a high nutritional value, which is partly attributed to their protein composition. Protein is mainly stored in the endosperm. Due to their well-balanced essential amino acid composition and abundant amounts of sulfur-rich amino acids, they possess an outstanding protein quality. In case of buckwheat cysteine can be limiting in some tartary buckwheat varieties, while in canihua rather threonine is limiting (Gallego et al., 2014; Bhinder et al., 2020). Protein content of seeds can vary from 5.7 to $14.2 \%$ for buckwheat, $13.1-21.5 \%$ in amaranth, $9.1-16.7 \%$ in quinoa and 12-19\% in canihua (D’Amico et al., 2017; Martínez-Villaluenga et al., 2020). The main storage proteins found in dicotyledonous plants are globulins and albumins, which make up 60$70 \%$ of the protein fractions. In terms of distribution, protein fractions of pseudocereals generally display a closer similitude to legumes than to cereal proteins (Janssen et al., 2017).

In amaranth seeds, protein is distributed in higher amounts in the embryo (65\%), which is rich in lysine. The rest is found in the perisperm and usually contains lower amounts of lysine (Martinez-Lopez et al., 2020). According to their solubility, amaranth proteins mainly consist of $11-52 \%$ of albumins, $16-51 \%$ of globulins and $7-36 \%$ of glutelins and $0-13 \%$ of prolamins (Janssen et al., 2017). Two main storage proteins can be found in amaranth: amarantin (globulin 11S), which is the most important and abundant storage protein and conamarantin (globulin 7S) that is found in significantly lower amounts and has been less studied (D'Amico et al., 2017). 
In case of buckwheat, protein content increases from the inner (1-2\%) to the outer fractions ( $\sim 40 \%)$ of the grain, being highest in the embryo ( $56 \%)$. According to the Osbourne classification, Janssen et al. (2017) reported that $18-44 \%$ albumins, 5-70\% globulins, $4-37 \%$ glutelins and $0-11 \%$ prolamins can be found in buckwheat. The very large deviations in each fraction is mainly attributed to different methodological approaches chosen for quantification. Overall, tartary buckwheat displayed a slightly higher albumin, glutelin and prolamin content, compared to common buckwheat. The most abundant storage protein found in buckwheat is globulin 13S, followed by a minor amount of globulin 8S (D’Amico et al., 2017).

Quinoa proteins are mainly stored in the embryo and endosperm and are used for growth and development. Depending on the variety, albumins in quinoa range from 13 to $29 \%$, globulins from 56 to $34 \%$, prolamins from 0 to $4 \%$ and glutelins from 5 to $36 \%$ (Janssen et al., 2017). The main storage proteins are $11 \mathrm{~S}$ globulin and $2 \mathrm{~S}$ albumin. In terms of quality, quinoa is considered one of the best vegetable proteins, as its biological value is similar to that in casein ( $73 \%$ ) (Gordillo-Bastidas et al., 2016). In contrast to quinoa, little has been studied on canihua. Globulins (24.1-26.3\%) and glutelins (21.5-22.9\%) comprise the main protein fractions, followed by albumins (15.4-15.8\%) and prolamins (9.6-9.9\%) (Moscoso-Mujica et al., 2017). Its protein quality is high due to the amount of essential amino acids, obtaining a chemical score of 91-93.3\% (Gallego et al., 2014).

\subsection{Fat/lipids}

Total lipid content of pseudocereals are generally higher (quinoa: 4.0-7.6\%, canihua: 5.0-8.0\%, amaranth: $5.6-10.9 \%$, buckwheat: $0.75-7.7 \%$ ) than those found in other grains such as wheat, corn or sorghum, except for buckwheat. In all of them, the highest proportion of lipids are unsaturated fatty acids (quinoa: 71.0-84.5\%; amaranth: 61.0-87.3\%; buckwheat: $80.1-80.9 \%$ ) from which linoleic acid and oleic acid are the most abundant (De Bock et al., 2021). Amaranth, canihua and quinoa show higher concentrations of linoleic acid, compared to oleic acid, whereas buckwheat displays similar proportions of both fatty acids. Some of these grains even contain significant amounts of linolenic acid being most abundant in quinoa (3.0-11.1\%), followed by canihua (1.2-6.1\%) and buckwheat (0.0-5.3\%) (Martínez-Villaluenga et al., 2020). In regards to saturated fatty acid, the most abundant fatty acid in all cases is palmitic acid, which is present in concentrations of $9.3-20.2 \%$.

\subsection{Micronutrients - vitamins, minerals, secondary plant metabolites}

Pseudocereals are mostly known by their outstanding micronutrient content. Most of the minerals are located in the bran of the grain. The main minerals found in these pseudocereals are potassium, phosphorous and magnesium, from which amaranth contains the highest amount of minerals, followed by quinoa and buckwheat. They are also a good source of iron, zinc, calcium, manganese and copper, which are found in higher amounts than in cereals (Reguera and Haros, 2017). Pseudocereals also contain a small amount of antinutritive compounds such as phytate, which hinder the absorption of minerals. For example, saponin has to be removed in some quinoa varieties before consumption, as it interferes with the digestibility and palatability (e.g. bitterness) of the grain. With regards to vitamins, quinoa, amaranth and canihua are good sources of vitamin E (Niro et al., 2019). Quinoa and amaranth are also a good source of folic acid, riboflavin and vitamin C. Moreover, quinoa also contains significant amounts of $\alpha$-carotene, even 
ten times higher than that found in wheat. Buckwheat is rich in thiamine and vitamin $\mathrm{C}$, as well as tocopherols, which is higher in tartary buckwheat than common buckwheat. Gammatocopherol is the main tocopherol found in these seeds (Reguera and Haros, 2017).

Polyphenols are the most abundant secondary plant metabolites found in pseudocereals. Di Cairano et al. (2020) compared 12 cereals and legumes and determined the highest total phenolic content in buckwheat, followed by quinoa. Buckwheat possessed the highest flavonoid content, while amaranth displayed moderate amounts of both compounds. Further research has reported 106 compounds of phytochemicals in buckwheat, that can be broadly classified into phenolic compounds, flavonoids, triterpenoids, steroids, fagopyritols and fatty acids, from which the first two compose the major source of bioactive components (Jing et al., 2016). Pereira et al. (2020) revealed quercetin and kaempferol derivatives the main components in black, red and white quinoa and Penarrieta et al. (2008) identified catechin gallate, catechin, vanillic acid, kaempferol, ferulic acid, quercetin, resorcinol and 4-methylresorcinol as the main eight compounds found in canihua. Pigmented quinoa varieties and canihua showed a significant amount of $\beta$-carotene and lutein and possessed one of the highest carotenoid contents among nine tested gluten-free cereals and pseudocereals (Niro et al., 2019).

\subsection{Health benefits}

Since pseudocereals represent a good source of bioactive compounds, they have been closely related to many health benefits such as antioxidant, anticancer, immunomodulating and gastroprotecting properties, which support the prevention and/or treatment of several diseases. Nevertheless, the amount of clinical trials and animal studies for supporting these health claims still remains limited.

A good amount of pharmacological studies have corroborated that buckwheat possesses antidiabetic, antitumor, antioxidant, hepatoprotective and anti-inflammatory effects (Jing et al., 2016). Quinoa has shown to improve serum lipid profile in blood and decrease the risk of cardiovascular disease and type 2 diabetes (Karimian et al., 2021). Amaranth has been characterized by its antibacterial and antifungal activities, while amaranth protein-based diets have shown to improve glucose tolerance, increase plasma insulin and reduce food intake (MartínezVillaluenga et al., 2020). Ranilla et al. (2009) studied the potential of canihua to manage type 2 diabetes hypertension and hyperglycaemia and found that canihua displayed one of the highest antioxidant activities among the tested grains.

Besides the high nutritional value in wholegrain, recent research has identified that in particular the protein and peptides from pseudocereals may promote several health benefits for reducing chronic inflammation and oxidative stress, which plays a major role in age-related diseases and in some forms of cancer. The albumin fraction showed general higher immunemodulating and antioxidant activities (Capraro et al., 2021).

Tartary buckwheat peptides have shown several in-vivo and in-vitro biological activities. A detailed review of Zhu (2021) summarizes that these peptides display a huge range of health promoting benefits, such as the ability to modulate gut microbiota, prevent cardiovascular diseases, lower blood pressure and blood cholesterol levels, and show antidiabetic and immunomodulatory capacities. According to Martínez-Villaluenga et al. (2020) amaranth and quinoa protein hydrolyzates have displayed promising anticancer and significant anti-hypertensive and anti-thrombotic activities. 


\section{PHYSICAL PROPERTIES}

Physical properties like water binding and swelling capacity, foaming and emulsification ability, or pasting characteristics are important factors that influence food processing and development. They are highly influenced by the chemical composition, especially by starch and protein compounds. Starch damage can significantly influence the physical properties of flours such as water absorption or pasting, which is determined by the milling technique. De Bock et al. (2021) reported that starch damage was higher in quinoa (3.51-4.44\%) than in amaranth $(3.10-3.95 \%)$, due to the larger particle size. Nevertheless, buckwheat displayed the lowest starch damage (0.93-1.43\%), due to its less compact structure, which allows an easier and gentler milling process. Di Cairano et al. (2020) studied the functional properties of gluten-free flours obtained from cereals, pseudocereals and legume flours. Results showed that water and oil absorption capacity remained similar between pseudocereals in a range of $1.22-1.45 \mathrm{~g} / \mathrm{g}$ and $1.06-1.75 \mathrm{~g} / \mathrm{g}$, respectively. The water solubility index of the pseudocereals ranged between 6.22 and $10.22 \mathrm{~g} /$ $100 \mathrm{~g}$ and was found to be higher than in cereals, but mostly lower than in legumes. Due to its high protein content, amaranth flour has been characterized by highest water holding capacity within all pseudocereals, ranging between 1.60 and $2.15 \mathrm{~g} / \mathrm{g}$ (De Bock et al., 2021). This has been especially useful during extrusion cooking, as it allows greater expansion of the extrudate, compared to other GF flours. Similar conclusions were drawn by Ramos Diaz et al. (2013) in which corn-based extrudates containing $20 \%$ of amaranth, quinoa or canihua were compared. Water absorption capacities of quinoa are usually lower than that found in amaranth, ranging between 0.89 and $1.74 \mathrm{~g} / \mathrm{g}$, while values reported for buckwheat and canihua were $1.67-2.73 \mathrm{~g} / \mathrm{g}$ and 1.54-1.94 g/g, respectively (Aluwi et al., 2017; Bustos et al., 2019; Bhinder et al., 2020; De Bock et al., 2021). It has been also reported that amaranth improves viscoelastic properties of gluten-free batters and that some of its functional properties, such as water and fat absorption capacity can even be enhanced by popping of the seeds (Liu et al., 2019).

Swelling behavior is different for each pseudocereal, as starch granules are organized differently within the grains, and it closely depends on the amylopectin content. De Bock et al. (2021) characterized the swelling and pasting properties of buckwheat, quinoa and amaranth wholemeal flour. They concluded that amaranth displayed the highest swelling power amongst pseudocereals. However, its pasting properties showed that the starch exhibited the lowest shear stability, which was attributed to the low amylose content of the grain. Quinoa and buckwheat showed less sensitivity towards shearing, which were more likely stabilized by amylose-lipid complexes. This was also seen by Bhinder et al. (2020) and Aluwi et al. (2017), who evaluated flour from twenty-three tartary buckwheat and twenty-eight quinoa varieties, respectively. Bhinder et al. (2020) observed very low set back and breakdown viscosities in most buckwheat flours, indicating a high paste stability and lower retrogradation, which would make the flours a promising thickener for sauces and soups. On the other hand, Aluwi et al. (2017) reported that quinoa followed a similar amylograph pattern than that found in pea and other legume starches, exhibiting low swelling and high hot paste stability. These properties might be useful in processes where food is exposed to high heat treatments and mechanical shearing. Although not much research is available for canihua, the study of Fuentes et al. (2019) revealed a similar pasting behavior to quinoa, exhibiting very low breakdown and a high shear and temperature stability. This was attributed to the small granule size of canihua, which showed a lower 
Table 1. Physical, structural and processing properties of pseudocereals

Seed kernels morphology

Starch properties

Protein properties

Water binding properties
Small kernels - a, q, c

Triangle shaped $-\mathrm{b}$

Ring embryo - a, q, c

Dense and compact seed hull - a

Saponins $-\mathrm{q}$

Weak starch crystallinity

Low amylose content - a, q, c

High amylose content $-b$

Low starch gelatinization temperature

High viscosity

High hot paste viscosity and stability, low breakdown - q, b

Slow starch retrogradation - a, q, c

Medium to high starch retrogradation - $b$

Low starch damage upon milling $-\mathrm{a}, \mathrm{b}$

Low-medium starch damage upon milling - q, c

Good freeze-thaw stability

Low in prolamins

Gluten-free

No network formation

Low protein solubility

Good emulsification properties

Good foamability and foam stability (especially in b)

High water solubility index and water absorption capacity

(especially in a)

$\mathrm{a}$ - amaranth; q - quinoa; $\mathrm{c}$ - canihua; $\mathrm{b}$ - buckwheat.

tendency to rupture. Moreover, canihua starches displayed a higher paste firmness and a higher retrogradation than that obtained by quinoa starch (Steffolani et al., 2013).

With regards to protein functionality, so far amaranth proteins have been more extensively investigated than those of quinoa and buckwheat. Overall, protein solubility of these pseudocereals is low, ranging from 2 to $35 \%$ at acidic conditions ( $\mathrm{pH}$ : 3.0-5.0), although a higher solubility is generally found at more alkaline $\mathrm{pH}$ (Janssen et al., 2017). For example, in case of buckwheat protein, the good foamability and foam stability are attributed to the globulin fraction, which are higher than for soy (Choi and Ma, 2006). This was also seen by Bhinder et al. (2020), who determined four tartary buckwheat varieties that exhibited good foaming and emulsifying properties, which could be potentially and resourceful in gluten-free eggless cakes. Table 1 summarizes the major physical and processing properties of pseudocereals, influenced by their structural characteristics.

\section{PROCESSING AND FOODS}

\subsection{General considerations for processing pseudocereals}

Pseudocereals can be used in food processing as any other starchy grain, either in from of whole seeds, but they can also be milled and fractionated. Yet, due to their distinct botanical classification 
and chemical composition, pseudocereals perform differently and often require specific process conditions or adaptations. A sound knowledge on fundamental physical and technological properties of these raw materials is a first step towards an efficient and successful application of pseudocereals for processing and food development. In this section the technological properties of pseudocereals shall be described, based on their specific chemical composition.

The major factors that have to be considered when using pseudocereals are their small seed kernel size and different botanical structure, their gluten-free and thus lack of network-forming properties, as well as their small starch granule size and starch structure. These parameters all result in different technological properties compared to true cereal and can be challenging for processing, in particular when aiming at incorporating pseudocereals in common products. On the other hand, they offer unique opportunities, which can be exploited for specific food applications and thus be beneficial for the development of new and innovative food products.

4.1.1. Seed morphology and botanical structure require process adaptations. All pseudocereal seeds, in particular amaranth, quinoa and canihua are rather small, and they differ in botanical structure. Already these features ask for different milling conditions for these grains, in particular for the production of milling fractions of amaranth and quinoa, where an extensive adaption of the milling protocol is required, in order to obtain chemically distinct flour fractions. For buckwheat milling, it is the triangle shape of the kernel that is challenging. Therefore, all three pseudocereals are still mostly milled to wholemeal flour, for which most common mills can be employed. In terms of nutritional quality this can be considered an advantage, as an increased consumption of wholemeal flour is recommended. Amaranth seeds are additionally characterized by a very compact and dense seed hull, which is another factor that needs to be considered for milling. Increasing the seed moisture before milling seems to be necessary. On the other hand, this horny seed hull enables the seeds to be popped without pressure when subjected to intense, dry heat. Within the true cereals this can only be done with maize kernels. Popped amaranth can be used either directly for consumption or prior milled to flour.

4.1.2. Saponin removal of quinoa. For quinoa the saponin content has to be considered, as they taste rather bitter when present in too high amounts. Therefore, quinoa is usually desaponified prior to its use. Methods to remove saponin can be dry methods by abrasive milling or wet methods, by washing. For washing the grains are soaked or rinsed in excess water until no foam appears. This involves a high amount of water, which needs to be purified before deposit. After application of wet methods, the quinoa grains need to be dried in warm air to below 15\% seed moisture. Also combinations of dry and wet methods are applied. In Peru and Ecuador, saponins are traditionally removed from quinoa by manual washing with a large amount of water on an abrasive (stone) surface until the outer layers of the grain are removed. Dry and wet combinations are mostly used in industrial scale processes today, in order to meet the market quality standards. Various apparatus have been developed for this purpose.

4.1.3. Gluten-free properties. The fact that pseudocereals do not possess any network forming properties makes it difficult to produce leavened products or to create volume in bakery products. After a certain level of incorporation into such products, changes in quality will arise and require a holistic adaptation of recipe and/or processing. On the other hand, as the supply for nutritious gluten-free product is still a significant market segment, their increased use for the 
development of gluten-free products has been suggested for years, due to their excellent nutritional properties. Yet, the sales offer of such products could still be fostered.

4.1.4. Starch properties. As described before, the starch composition, in particular the amylose content, and the structure of the starch kernel in pseudocereals vary significantly from cereals, resulting in altered and specific physicochemical properties. Starch gelatinization and pasting properties play a major role and are thus of great interest for processing and food development of starchy raw materials. Srichuwong et al. (2017) performed a detailed study on the physicochemical properties of starch in amaranth and quinoa. Gelatinization temperature as measured by DSC were at 57.4 and $58.3^{\circ} \mathrm{C}$ in quinoa and amaranth, respectively, which is lower than for cereals and is most likely due to the weaker crystalline structure. Starch gelatinization and retrogradation is influenced by the amount of amylopectin, but also by other components present in the flour like proteins, dietary fibre (in particular soluble dietary fibre) and eventually other hydrophilic compounds, which compete with starch for hydration, and thus delay starch gelatinization temperature and shift it to higher values. Starch retrogradation is an important factor that needs to be considered for food development of starchy foods. Amylose is known to retrograde fast, and determines gel structure of the starch paste after cooking or processing. Retrogradation of amylopectin happens only slowly and thus can define texture, stability and shelf-life of starchbased products. Amaranth and quinoa starches tend to retrograde slowly, mainly because of their low amylose content, but also the high content of soluble dietary fibre seemed to retard retrogradation (Srichuwong et al., 2017). Pasting properties measured by a viscoanalyzer (RVA) revealed that amaranth and in particular canihua and quinoa show high peak viscosities and a small breakdown (Srichuwong et al., 2017; Repo-Carrasco-Valencia et al., 2010). Generally, peak viscosity might be influenced by the formation of amylose-lipid complexes, that can restrict granular swelling, decrease peak viscosity and breakdown. These particular starch properties suggest a beneficial use of pseudocereal starch or flours as a natural food thickener or the use for products with intended long shelf life, in particular for frozen products.

\subsection{Traditional processing}

The use of pseudocereals has a long tradition for human nutrition and several food processes have been developed and applied by the indigenous peoples in history. Traditional dishes and products were soups, porridges, alcoholic and non-alcoholic, fermented or non-fermented beverages, as well as a range of fried and cooked foods. Aztecs used amaranth in beverages and sauces, or for producing tortilla. In Ecuador, for example, the range of quinoa products that are produced and marketed include: whole grain, quinoa flour, quinoa flour mixtures with oats or amaranth, baby food porridge, granola, energy bars, soft drinks, quinoa expanded as breakfast cereal, biscuits, alfajores (a traditional dessert), and quinoa bread with substitution percentages reaching 30\%. Also solid fermentation processes are being tested to obtain vegetable meat alternatives and technologies are being optimized to produce milk- and yogurt-type drinks (Hinojosa et al., 2021). Buckwheat is used in many countries for gruels, porridges and pancake cooking. Often these buckwheat products are made with sourdough. And also for buckwheat solid-state fermentation is investigated for future exploitation (Petrova and Petrov, 2020).

Today, a wide range of products from pseudocereals is available in most countries worldwide, same in the Northern Countries as in the countries of their origin (see Fig. 1). In particular quinoa can be found in one or the other form in almost all food categories. When using these 

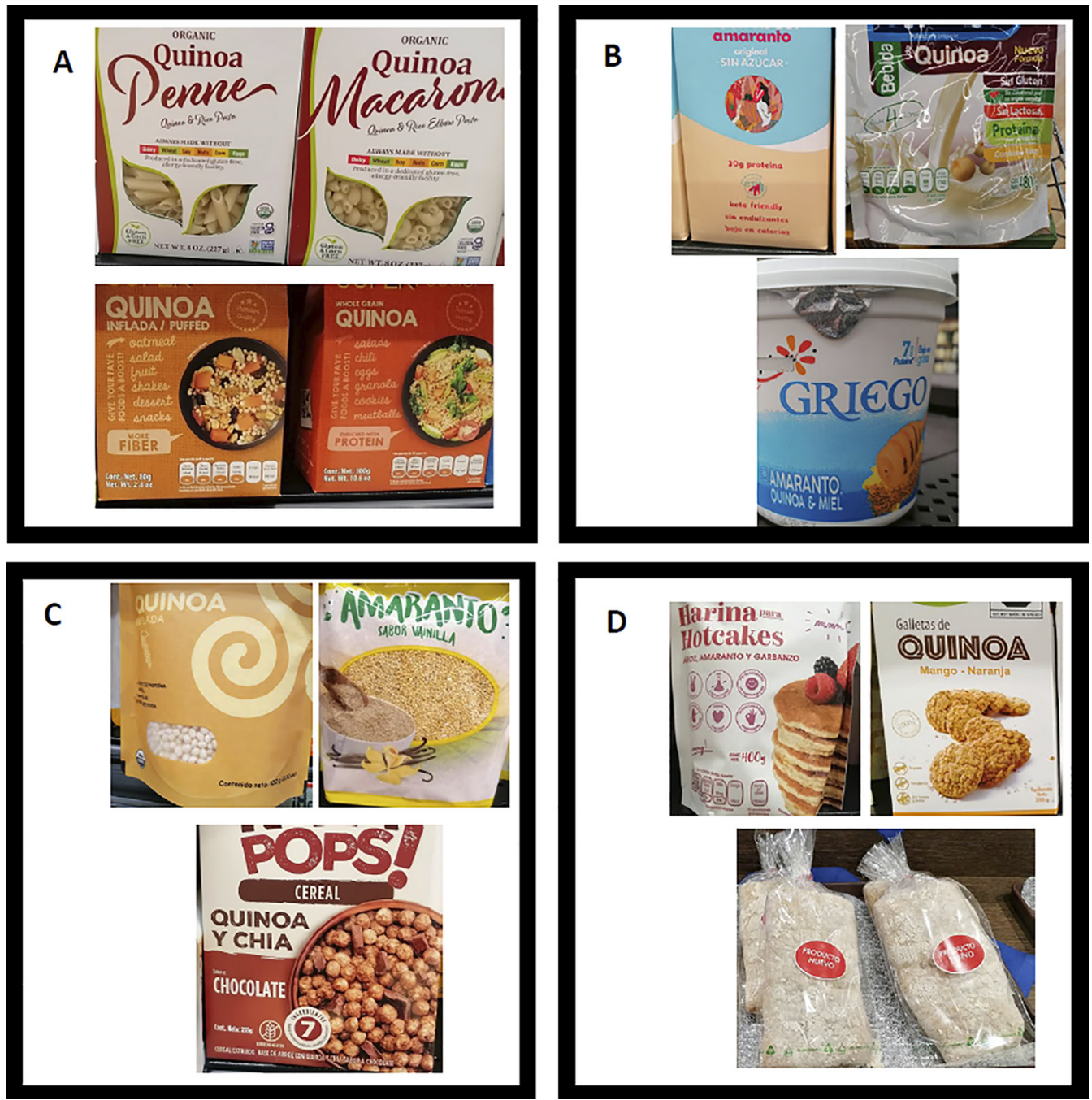

Fig. 1. Overview of food applications of pseudocereals. A. Pasta and convenience products; B. Pseudocereal milk (powder, pasteurized), yogurt with added pseudocereals; C. Puffed and extruded pseudocereals; D. Bakery products: pancake flour blend, cookies and ciabbata (photos @ Silvia Bender, 2021)

grains for modern food use, it may be wise to consider some of the traditional processes and the developed know-how for its use.

4.2.1. Popping, puffing, roasting, toasting and flaking. Typically, amaranth, quinoa and canihua were used either as whole, unground grains or as milled flours. Specific processes that were developed and applied traditionally for the use of these grains, were roasting, toasting, puffing and popping, where the grains are subjected to high and dry heat for a certain time, 
which usually is very short, only seconds or a few minutes. Depending on the temperature and inherent seed moisture, the seeds are either roasted or popped.

With regard to amaranth no pressure is needed to pop the seeds, while quinoa grains like most cereals, can only be puffed when pressure is applied. Amaranth popping requires extremely high heat and a seed moisture of at least $12-14 \%$ (own investigations, unpublished). The internal water within the seed evaporates explosively, causing the seed to expand to several-fold in size. Traditionally, the seeds were poured on a very hot surface like a hot plate or pan (without fat), which is principally a rather simple process, but it can only be performed batch-wise and temperature and exposure time is rather difficult to control. For industrial scale, several equipment that apply hot-air heating like continuous fluidized bed systems have been developed (Murakami et al., 2014). The advantage of these approaches is the fact, that the popped kernels are blown out from the hot temperature zone immediately, so a too long heat exposure or burning of the sensitive popped seeds can be prevented. For producing expanded or puffed quinoa, the grains (14-15\% seed moisture) are pressure-cooked at high temperature and subsequently expelled. The sudden drop in temperature and pressure then causes the grain to expand. Roasting is a typical process applied for quinoa and canihua in the Andean region. The roasted grain is consumed directly or ground into an instant product, often mixed with milk or water to be consumed as a beverage or porridge.

All these heat treatments cause significant changes in the physical, nutritional and sensory properties of the resulting product. By popping or puffing, the starch is fully gelatinized and the protein is denatured. Therefore, popped amaranth and puffed quinoa are ready-to-eat products, which can be consumed directly or further milled to flours. In terms of nutritional quality of the roasted or popped seeds, although as for any heat treatment process, a loss of some nutrients to a certain extent has to be considered (Quiroga Ledezma, 2015), it is overall rather low, as exposure time to heat is short. Still, careful processing has to be considered. Murakami et al. (2014) found that popping using a fluidized bed system $\left(260^{\circ} \mathrm{C}, 15 \mathrm{~s}\right)$ did not affect the content of B-group vitamins, and the recovery for essential and trace elements was high. Quinoa puffing on the other hand seems to deteriorate the final quality more significantly as protein levels can be reduced, as well as some essentials fatty acids (Villacres et al., 2013).

Flaking of amaranth and quinoa is performed by conditioning the seeds to around $15-16 \%$ and pressing the grains between two converging rollers, similar to oat flakes. The produced flakes can then be added to juices, soups, pies or bakery products. Compared to grains, flakes require less cooking time.

Regarding the sensory properties, roasted, toasted, popped or flaked seeds have a nice nutty and roasted flavor, which can be an additional advantage for its further food use. Popped or puffed grains can be added as an ingredient or topping directly to almost any food like salads, soups, sauces, or desserts. A traditional product that has been developed by the historic people in Latin America, is "alegría" (see Fig. 2), a snack bar, where popped amaranth seeds are bound by molasses, honey, sugar syrup or similar. This product is still common today, not only in Latin America, it is also available more frequently in the Northern countries. Also puffed quinoa is used in similar energy bars. When the popped or puffed seeds are milled to flour, their subsequent use can broaden the range of food applications, like soups, sauces, beverages, desserts, but also bakery products. Yet, it has to be considered, that this flour is already pre-gelatinized, which can be an advantage as it functions as cold-soluble instant flour. For bakery products its amount of incorporation might be limited tough, due to its higher water adsorption properties. 

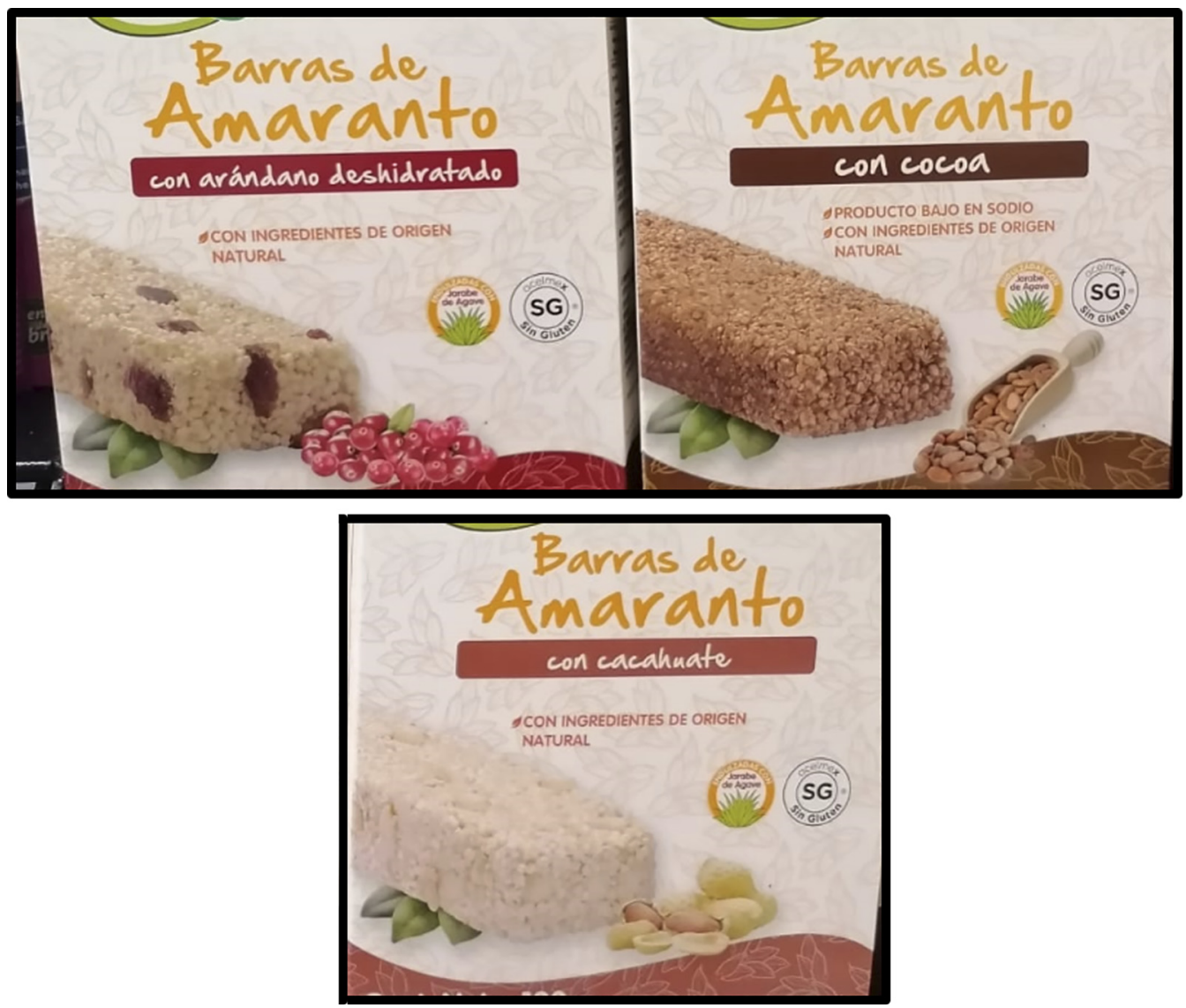

Fig. 2. Modern amaranth snack called "alegría" added with cranberry, cocoa powder or peanuts (photos (C) Silvia Bender, 2021)

\subsection{Bakery products \& sourdough}

Pseudocereals have been widely used and studied for the production of bakery products, from which bread is the most common. Mainly blends with these have been used for enriching the nutritional properties of wheat formulations as they are often made from refined flour. Blends with small substitutions may even result beneficial, as in the last couple of years, wheat doughs have shown an unusually strong gluten network in some European countries, due to the effect of climate change. This can cause difficulties in baking, especially in fine bakery (own data, not published).

From all pseudocereals, amaranth has been the most studied for breadmaking (Haros and Sanz-Penella, 2017). Kurek and Krzemińska (2020) suggested that already 5\% of amaranth was enough to preserve the bread quality, although overall the crumb hardness decreased with addition of amaranth up to $15 \%$ and a $10-15 \%$ addition even retarded staling. Anti-staling properties of pseudocereals have also been reported in rice-based breads added with up to $30 \%$ 
unhusked buckwheat flour (Torbica et al., 2010). In regards to quinoa, one study even suggested that it may have the potential to reduce the glycemic index value of bread (Wang et al., 2021). These authors evaluated the effect of whole quinoa flour on the texture and in-vitro starch digestibility of wheat bread. Quinoa addition decreased the specific volume of wheat bread but did not significantly affect the hardness and chewiness of the crumb when substituted at $20 \%$. Interestingly, a reduction of up to $17 \%$ starch digestibility was observed, when compared to the control. This could be explained by the B-type starch granules of quinoa and wheat, which remained mostly intact and wrapped within the protein-sugar-oil film after baking. Quinoa has therefore the potential to develop breads with lower glycemic index values.

Pure pseudocereal bread formulations are generally more difficult to handle and lack the technological properties of wheat, due to the absence of gluten. Even higher amounts of pseudocereals in blends (30\% and more) may already lead to more moist and shorter doughs with poor viscoelastic properties and fermentation tolerances as well as very compact structures (Bender and Schönlechner, 2020), as seen in many studies. Sluková et al. (2017) studied the mixing behavior of buckwheat dough compared with wheat dough. The authors found that in contrast to wheat, a continuous protein phase with suspended starch granules was absent in an optimally developed buckwheat dough. The fine and discontinuous coating enclosing the starch granules did not form filaments, as it is seen in gluten. Overmixing caused significant disintegration of the coating enclosing starch, although overall structural changes of the buckwheat dough remained very small when compared to the overmixed wheat dough. A similar study was carried out by Rosell et al. (2009), who studied the baking and rheological properties of wheat doughs added with canihua, amaranth or quinoa, compared to $100 \%$ pseudocereal flours. They reported that no breads with aerated crumb structures were obtained with the addition of $100 \%$ pseudocereal flours, except for quinoa. Pure canihua dough exhibited very low torque during its rheological characterization, showing low mechanical stability and consistency during mixing. Similar effects were seen in pure amaranth after reaching gelatinization. In case of quinoa, a low but measurable dough consistency was reported, which required higher pasting temperatures, compared to wheat. They concluded that the maximal replacement of wheat flour to obtain sensory acceptable breads was $25 \%$ canihua or quinoa and $50 \%$ amaranth.

Another possibility to introduce pseudocereals into bread could be the production of fibrerich milling fractions, which could serve as natural hydrocolloids (Ballester-Sánchez et al., 2020).

On the other hand, sourdough technology has been widely used to improve the technological, nutritional and sensory properties of breads. Sourdough can enhance gas retention, crumb structure, flavor, mineral bioavailability, starch digestibility and concentration of bioactive compounds and shelf life by retarding staling and protecting the bread from mold and bacterial spoilage, when used in the right proportion (Houben et al., 2010, Moroni et al., 2011, Bender et al., 2018). All these effects can be attributed to the metabolic activities of the lactic acid bacteria and yeasts.

Pseudocereal sourdough fermentation has shown to improve the rheological (e.g., viscoelasticity and network formation strength) and functional properties of gluten-free bakery products (Houben et al., 2010, Moroni et al., 2011, Bender et al., 2018). It has also been used to enhance the bioaccessibility and bioavailability of nutrients, mainly by increasing the degradation of phytase content of pseudocereal seeds or flours (Castro-Alba et al., 2019, Rocchetti et al., 2019). 
Other baking goods that have been produced from flour blends with pseudocereals are muffins, biscuits, cookies and cakes (Bhaduri, 2013; Martínez-Villaluenga et al., 2020). These have been carried out mainly to improve the composition of the final product, as they are generally low in fibre, and high in fat and sugar. In some cases, the technological quality of the product could be increased. For example, it was shown that by substitution in an appropriate amount, the nutritional and technological quality of muffins or cookies and even the shelf life of the product could be enhanced (Bhaduri, 2013, Dapčević Hadnadev et al., 2013; Antoniewska et al., 2018). If a 100\% pseudocereal formulation is intended, the texture and color can be controlled to some extent by baking parameters (temperature - time), and other ingredients (fat, sugar), to produce acceptable products (Jan et al., 2018).

\subsection{Extrusion cooking}

Extrusion cooking is a process where at high temperatures and high pressure, induced by high shear forces, starchy materials is cooked and transformed into ready-to-eat products in a very short time. Starch is gelatinized, the proteins are denatured, while nutrients are retained to a high extend, due to the rather short exposure to heat. The obtained extrudates can be formulated and consumed directly as snacks or breakfast cereals, overall, a wide range of consumer endproducts can be manufactured by this technology.

For the production of expanded extrudates no network forming proteins are required, thus this process is appropriate for pseudocereals. Research with the aim to study the applicability and adapt process parameters for extrusion cooking of pseudocereals or to develop defined endproducts has been undertaken and published by several authors. Generally, all pseudocereals require higher shear forces compared to rice or maize flour and longer residence times within the extruder barrel, due to their higher lipid and lower amylose content, which has to be considered particularly for extrusion cooking of amaranth and quinoa, as their fat content is rather high. Most extruders that are applied in the food industry, deliver well expanded products from flours or blends with a maximum fat content of around 5\%, especially when applying a twin-screw extruder that is typically used to produce expanded products. Amaranth and quinoa are therefore usually blended with flour or starches that have a lower fat content, like rice or maize. Alternatively, they can also be defatted prior to extrusion cooking, which includes an additional processing step. In the case of buckwheat, its fat content is lower, around $2-3 \%$ and can thus be extruded directly. Interesting for extrusion cooking of amaranth and quinoa is, that they can be introduced into the extruder in form of whole grains without prior milling, due to their small seed size. The high shear forces within the extruder are able to process and transform these kernels into well expanded extrudates. Ramos Diaz et al. (2017) investigated the extrusion cooking properties of maize blended with amaranth or quinoa, and achieved expanded extrudates even at an addition level of up to $50 \%$. Content of fatty acids and tocopherols were reduced in the extrudates, while the content of total phenolic compounds and folate were only little affected. This study proved that extrudates containing up to $50 \%$ amaranth or quinoa can maintain some key physical properties (e.g., high SEI, low stiffness) and the added nutritional value (e.g., increased content of folate). Replacement of wheat or maize by amaranth or buckwheat flours for the production of changed the nutritional quality of extruded breakfast cereals also in the study of Brennan et al. (2012). All of the extruded products made with the inclusion of pseudocereals showed a significant reduction in readily digestible carbohydrates and 
slowly digestible carbohydrates compared to the control product during predictive in vitro glycemic profiling. For quinoa it was shown that extrusion cooking increased protein crosslinking in quinoa and the amount of soluble fibre (Kuktaite et al., 2021). The content of essential amino acids was only reduced to a minor extent; only valine and methionine were reduced slightly greater, still the final product met the requirements of the Food and Drug Organization. For quinoa starch it could be observed that after extrusion cooking the starch is not completely gelatinized (own research investigations, not published), which is most like resulting from the specific starch granule characteristics, in particular the presence of aggregated starch compounds. A strategy to foster starch gelatinization in quinoa might be pursued by adding higher amounts of water during extrusion cooking followed by subsequent drying of the extrudates. Kuktaite et al. (2021) has shown that starch crystallinity decreased in particular during the postprocessing heating step.

Extrusion cooking not allows the production of ready-to-eat products. The extrudates can be milled after cooking, which offers the possibility to produce pre-gelatinized, instant flour flours with altered techno-functional properties. Extruded flours are characterized by a loss in hot paste viscosity, reduced final viscosity and high apparent viscosity under cold conditions. Hydration properties and water solubility index are increased, also oil binding capacity protein solubility and foaming properties are affected (Espinosa-Ramírez et al., 2021). For such flours there is a wide range of application in the food industry, in general, but also in the view of being physically modified flours and thus a food ingredient in terms of labeling, they might be used to replace food additives (e.g. thickeners).

\subsection{Non-dairy beverages, gruels and porridges}

Cereal beverages are indigenous to many regions in the world, but also in the Northern Countries they are more commonly consumed as an alternative to milk or to complement a healthy, or environmentally friendly life style. The demand for non-dairy beverages based on plants is therefore a growing market. Principally such beverages can be produced by adopting mashing, cooking and hydrolysis processes, where enzymes are added to degrade the starch and protein component and to transform the solid grain or flour into a liquid product. Usually separation processes are applied, where parts of the solids are removed by e.g. decanting, in order to decrease the content of coarse particles, which otherwise may cause a sandy, rough mouthfeel. This process step can lead to a significant decrease of nutritional valuable components like proteins, dietary fibre and others. A careful and optimized process needs to be implemented.

Principally, such beverages can be produced from all starchy raw materials, from cereals, legumes, nuts and also from pseudocereals, which are particularly suitable due to their specific physical properties and high nutritional composition. Several research to investigate the production and potential of beverages from pseudocereals have been performed in the past (Haros and Sanz-Penella, 2017), and they can also be found on the sales market (see Fig. 1).

Latest research increasingly focusses on the use and potential of advanced methods and processes to optimize and improve the nutritional quality of such beverages. Lactic acid fermentation stands out in this respect, although this methodology has a long tradition in use. In some areas, e.g. Africa, lactic acid fermentation is a common and long known process to alter the sensory properties, as well as to improve the nutritional quality, e.g. increase of protein 
digestibility or the bioavailability of certain minerals or reduction of phytate content (Adeyanju et al., 2019), of such non-alcoholic and alcoholic beverages. Also, microbial fermentation proofed to be an efficient tool in increasing the total phenolic content and in vitro antioxidant potential in cooked quinoa seeds, cooking or toasting in itself already increased TPC in boiled or toasted quinoa and buckwheat seeds (Rocchetti et al., 2019). Traditionally common is the use of backslopping, where a small portion of previous fermented drink is used to inoculate a new batch of flour. Commercially such fermented beverages are produced by using a specific lactic acid starter culture. Adeyanju et al. (2019) investigated that already simple acidification by addition of lactic acid can provoke these positive effects, which thus provides a fast and easy process to improve the nutritional quality of such cereal-based beverages. An advantage of acidification or lactic acid fermentation is that such produced beverages may not need to be decanted in order to obtain a product with smooth texture and sensory appealing properties. This way they can be a good source of proteins, dietary fibre, minerals and vitamins. Depending on the degree of dilution in water the final products are either rather liquid beverages or thicker and resemble gruel or porridge types of products. Increased viscosity was shown to prevent phase separation and support overall shelf life (Ludena Urquizo et al., 2017).

Ludena Urquizo et al. (2017) developed a fermented beverage from quinoa and found that differences between quinoa varieties may have substantial effects on food processes and on the properties of final products. But all drinks had viable and stable microbiota during the storage time and the fermentation proved to be mostly homolactic. By selection of specific bacteria strains the properties of such beverages can be altered. Zannini et al. (2018) used the strain Weissella cibaria MG1, that is able to produce dextran, in wholemeal quinoa drink, to produce a high viscosity product that could be consumed as a non-dairy yoghurt alternative. Similar results were obtained by Lorusso et al. (2018) using Weissella confusa DSM 20194. Cardinali et al. (2021) tested a pool of 23 lactic acid bacteria strains for the fermentation of three ad hoc formulated cereal (red rice and barley) and pseudocereal (buckwheat) -based substrates. Eight strains with the best performance in terms of acidification rate were selected for the formulation of three multiple strain cultures to be further exploited for the manufacture of laboratory-scale prototypes of fermented beverages. The compositional and microbiological features of the three experimental beverages highlighted their high biological value and they all showed a high stability during storage of 30 days at $4{ }^{\circ} \mathrm{C}$. For the production of amaranth beverages, the use of popped flour has a high potential to improve the organoleptic properties, also it increases the viscosity of the final beverage, which was shown by own trials.

Another strategy to produce plant-based beverages that is increasingly pursued in recent years, is to formulate them based on isolated proteins. Manassero et al. (2020) developed such a high protein beverage based on amaranth proteins. Heat treatment and addition of gums like gellan and xanthan, generated macro complexes contributed to the colloidal stability of the amaranth-based beverage.

\subsection{Gluten-free products}

The most challenging task during the production of gluten-free products is to replace the functionality of gluten. In bread, raw materials need to replace the three-dimensional network that is built by gluten, while in pasta, they have to resemble the agglutination behavior and elasticity of the product. Until now, the most popular approach to imitate or substitute the 
gluten network is by adapting the gluten-free formulation. Alternatively, technological approaches have also been used to adjust or modify batter and bread properties (Bender and Schönlechner, 2020).

4.6.1. Bread. In the past years, the inclusion of pseudocereals in gluten-free recipes has been suggested to overcome the nutritional unbalance that is often related to a gluten-free diet (i.e. low dietary fibre and micronutrient content, high starch content). This has been successfully studied by blending pseudocereal flours with other gluten-free flours/starches or using them solely as the main ingredient in the formulation, especially in bread. Overall, blends have shown more promising in producing breads with better technological quality. According to Liu et al. (2019), amaranth-soy (85:15 and 70:30 ratio) and amaranth-lupin (85:15 ratio) improved bread properties such as bread firmness and volume compared to amaranth bread alone and were comparable to whole wheat breads. Moreover, it also enhanced the nutritional properties of the bread, due to its high value proteins and the high amount of nutrients in amaranth. Also, substitution of potato starch with amaranth or quinoa flour produced doughs with good leavening properties, that would be suitable for developing gluten-free bread.

On the other hand, less focus has been given on technological approaches, which can significantly improve gluten-free bread properties. These include processing methods such as sourdough technology, high hydrostatic pressure, milling and non-conventional baking methods (Bender and Schönlechner, 2020, Sciarini et al., 2020). For example, the use of sourdough improved the technological quality of buckwheat and amaranth bread (Houben et al., 2010; Bender et al., 2018). More recently, a very promising approach was used by Bender et al. (2019), who used ohmic heating as an alternative baking process in buckwheat breads. Results showed significant advantages in terms of functional properties and digestibility, compared to conventionally baked breads. Lastly, Sciarini et al. (2020) assessed the effect of particle size of different quinoa and buckwheat fractions on the gluten-free bread quality. A hammer mill, followed by cyclonic milling allowed them to obtain similar size fractions. It was seen that the finest fractions resulted in breads with higher technological quality, although the effect of the chemical composition of the fractions need to be considered.

4.6.2. Pasta. Regarding the production of gluten-free pasta, the addition of pseudocereals has been proposed by several authors, as well, in order to increase the nutritional and functional quality of pasta. In general, blends of cereals/beans with pseudocereals has been a popular approach to produce, both, gluten-containing and gluten-free, pasta. One example is the investigation of Schoenlechner et al. (2010) who investigated the potential of amaranth, quinoa and buckwheat to produce gluten-free pasta. Buckwheat revealed the least negative effects, while amaranth displayed a decrease in firmness and cooking time and quinoa in cooking loss. An optimized flour blend of amaranth, quinoa and buckwheat (20:20:60) was used to minimize these negative effects. It has been reported that a higher proportion of pseudocereal flour might lead to a decreased sensory acceptability (Gupta et al., 2021, Demir and Bilgiçli, 2021).

For the production of gluten-free pasta starch plays a major role. Technological approaches to improve the quality of gluten-free pasta are therefore to modify the starch properties, e.g. by pre-gelatinization. De Arcangelis et al. (2020) used gelatinized buckwheat flour alone or in combination with maize and rice and showed that gelatinization of the three flour blends allowed to obtain pasta with the highest quality and texture. On the other hand, Singh and Liu (2021) 
evaluated roasting and jet-cooking of amaranth flour to improve noodle making. Raw, jetcooked and roasted amaranth flour noodles were overall softer than those produced with wheat flour. Jet-cooking was less suitable for noodle making due to its partial disintegration of the pasta during cooking, whereas roasted amaranth flour showed a good potential for replacing wheat flour in gluten-free noodles. Further hydrothermal treatments have shown to improve the technological and physiological properties of amaranth pasta (Rudra et al., 2020), while the application of sourdough additionally improved the nutritional quality of quinoa pasta (Carrizo et al., 2020).

\subsection{Other foods and non-foods}

The application of pseudocereals has dramatically increased in food products and research has even extended to the non-food area. For example, buckwheat has been processed into a range of food products including yogurt, vinegar, dark sauce, tea and alcoholic beverages (Cai et al., 2015). The addition of fibre-rich milling fractions of quinoa have been used as binders for the production of bologna-type sausages. The fibre rich quinoa fraction increased the emulsion stability, decreased the lipid oxidation and water activity of the sausage. It was concluded that nitrite addition may not be necessary as the quinoa fractions already lent the product enough color (Fernández-López et al., 2020). Additionally, quinoa and buckwheat flour have been successfully used as binders for meat burgers, improving the nutritional, sensory and shelf-life properties (Bahmanyar et al., 2021). Due to its excellent freeze-thaw stability and low amylose content, amaranth and quinoa starch could be used as thickener for frozen food. As they also resist retrogradation, their application could be extended to salad dressings, cream soups, sauces and pie fillings.

In the non-food area buckwheat has been the most studied pseudocereal. Buckwheat protein from distillers dried grains has been used for developing composite edible films for food packaging (Wang et al., 2017) and buckwheat peptides might also be used as a functional ingredient for the development of neutraceuticals (Li et al., 2019). Also canihua flour has shown the ability to form adequate biofilms for food packaging application. They had a high blocking ability, as compared to polyethylene films and display less solubility and water permeability than those found in certain polysaccharide films (Salas-Valero et al., 2015).

\section{CONCLUSIONS AND FUTURE OUTLOOK}

Pseudocereals are interesting from many perspectives. On the one hand, they are characterized by a high nutritional quality, containing significant amounts of minerals, vitamins, plant secondary plant metabolites and other health beneficial nutrients. Their specific starch structure (small starch granule size and architecture, differing content of amylose) and protein composition (gluten-free and thus lack of network-forming properties) result in different technological properties compared to true cereal that can be challenging for processing. This has been seen in particular, when aiming at incorporating pseudocereals in common products, as the adaption of formulations or additional processing approaches are required. Therefore, research on their use has been intensified, continuously providing new data and in-depth knowledge in this respect. On the other hand, all pseudocereals are plants that can easily be adapted and cultivated in many different environments and they are particularly tolerant towards dry and hot climate conditions, which makes them important food security plants. Latest food market data show that all 
pseudocereals, but especially quinoa, can be found in a wide range of products. Quinoa cultivation has thus shifted from a traditional grown crop to a globally traded commodity. Intensified efforts and a holistic approach in all areas of production, trade and political regulation must be undertaken to ensure that these plants become and remain food security plants for all people.

\section{REFERENCES}

Adeyanju, A.A., Kruger, J., Taylor, J.R.N., and Duodu, K.G. (2019). Effects of different souring methods on the protein quality and iron and zinc bioaccessibilities of non-alcoholic beverages from sorghum and amaranth. International Journal of Food Science and Technology, 54(3): 798-809. https://doi.org/10. 1111/ijfs.13998.

Aluwi, N.A., Murphy, K.M., and Ganjyal, G.M. (2017). Physicochemical characterization of different varieties of quinoa. Cereal Chemistry, 94(5): 847-856. https://doi.org/10.1094/CCHEM-10-16-0251-R.

Antoniewska, A., Rutkowska, J., Pineda, M.M., and Adamska, A. (2018). Antioxidative, nutritional and sensory properties of muffins with buckwheat flakes and amaranth flour blend partially substituting for wheat flour. LWT - Food Science and Technology, 89: 217-223. https://doi.org/10.1016/j.lwt.2017.10.039.

Bahmanyar, F., Hosseini, S.M., Mirmoghtadaie, L., and Shojaee-Aliabadi, S. (2021). Effects of replacing soy protein and bread crumb with quinoa and buckwheat flour in functional beef burger formulation. Meat Science, 172: 108305. https://doi.org/10.1016/j.meatsci.2020.108305.

Ballester-Sánchez, J., Fernández-Espinar, M.T., and Haros, C.M. (2020). Isolation of red quinoa fibre by wet and dry milling and application as a potential functional bakery ingredient. Food Hydrocolloids, 101: 105513. https://doi.org/10.1016/j.foodhyd.2019.105513.

Bender, D., Fraberger, V., Szepasvári, P., D’Amico, S., Tömösközi, S., Cavazzi, G., Jäger, H., Domig, K.J. and Schoenlechner, R. (2018). Effects of selected lactobacilli on the functional properties and stability of gluten-free sourdough bread. European Food Research and Technology, 244(6): 1037-1046. https://doi. org/10.1007/s00217-017-3020-1.

Bender, D., Gratz, M., Vogt, S., Fauster, T., Wicki, B., Pichler, S., Kinner, M., Jäger, H., and Schoenlechner, R. (2019). Ohmic heating - a novel approach for gluten-free bread baking. Food and Bioprocess Technology, 12: 1603-1613. https://doi.org/10.1007/s11947-019-02324-9.

Bender, D. and Schönlechner, R. (2020). Innovative approaches towards improved gluten-free bread properties. Journal of Cereal Science, 91: 102904. https://doi.org/10.1016/j.jcs.2019.102904.

Bhaduri, S. (2013). A comprehensive study on physical properties of two gluten-free flour fortified muffins. Journal of Food Processing \& Technology, 4: 7. https://doi.org.10.4172/2157-7110.1000251.

Bhinder, S., Kaur, A., Singh, B., Yadav, M.P., and Singh, N. (2020). Proximate composition, amino acid profile, pasting and process characteristics of flour from different Tartary buckwheat varieties. Food Research International, 130: 108946. https://doi.org/10.1016/j.foodres.2019.108946.

Brennan, M.A., Menard, C., Roudaut, G., and Brennan, C.S. (2012). Amaranth, millet and buckwheat flours affect the physical properties of extruded breakfast cereals and modulates their potential glycaemic impact. Starch - Stärke, 64(5): 392-398. https://doi.org/10.1002/star.201100150.

Bustos, M.C., Ramos, M.I., Pérez, G.T., and León, A.E. (2019). Utilization of Kañawa (Chenopodium pallidicaule Aellen) flour in pasta making. Journal of Chemistry, 2019: 4385045. https://doi.org.10.1155/ 2019/4385045. 
Cai, Y.Z., Corke, H., Wang, D., and Li, W.D. (2015). Buckwheat: overview. In: Wrigley, C.W., Corke, H., Seethamaran, K., and Faubion, J. (Eds.), Encyclopedia of food grains, 2nd ed. Amsterdam, Elsevier, pp. 307-315.

Capraro, J., Benedetti, S.D., Heinzl, G.C., Scarafoni, A., and Magni, C. (2021). Bioactivities of pseudocereal fractionated seed proteins and derived peptides relevant for maintaining human well-being. International Journal of Molecular Sciences, 22(7): 3543.

Cardinali, F., Osimani, A., Milanović, V., Garofalo, C., and Aquilanti, L. (2021). Innovative fermented beverages made with red rice, barley, and buckwheat. Foods, 10(3): 613.

Carpita, N.C. and Gibeaut, D.M. (1993). Structural models of primary cell walls in flowering plants: consistency of molecular structure with the physical properties of the walls during growth. The Plant Journal, 3(1): 1-30. https://doi.org.10.1111/j.1365-313x.1993.tb00007.x.

Carrizo, S.L., de Moreno de LeBlanc, A., LeBlanc, J.G., and Rollán, G.C. (2020). Quinoa pasta fermented with lactic acid bacteria prevents nutritional deficiencies in mice. Food Research International, 127: 108735. https://doi.org/10.1016/j.foodres.2019.108735.

Castro-Alba, V., Lazarte, C.E., Perez-Rea, D., Carlsson, N.G., Almgren, A., Bergenståhl, B., and Granfeldt, Y. (2019). Fermentation of pseudocereals quinoa, canihua, and amaranth to improve mineral accessibility through degradation of phytate. Journal of the Science of Food and Agriculture, 99(11): 52395248. https://doi.org.10.1002/jsfa.9793.

Choi, S.-M. and Ma, C.-Y. (2006). Extraction, purification and characterization of globulin from common buckwheat (Fagopyrum esculentum Moench) seeds. Food Research International, 39(9): 974-981. https://doi.org/10.1016/j.foodres.2006.06.004.

D’Amico, S., Schoenlechner, R., Tömösközi, S., and Langó, B. (2017). Proteins and amino acids of kernels. In: Haros, C.M., and Schoenlechner, R. (Eds.), Pseudocereals, chemistry and technology. Wiley-Blackwell, Chichester, West Sussex, UK, pp. 94-118.

Dapčević Hadnadev, T.R., Torbica, A.M., and Hadnadev, M.S. (2013). Influence of buckwheat flour and carboxymethyl cellulose on rheological behaviour and baking performance of gluten-free cookie dough. Food and Bioprocess Technology, 6(7): 1770-1781. https://doi.org.10.1007/s11947-012-0841-6.

De Arcangelis, E., Cuomo, F., Trivisonno, M.C., Marconi, E., and Messia, M.C. (2020). Gelatinization and pasta making conditions for buckwheat gluten-free pasta. Journal of Cereal Science, 95: 103073. https:// doi.org/10.1016/j.jcs.2020.103073.

De Bock, P., Daelemans, L., Selis, L., Raes, K., Vermeir, P., Eeckhout, M., and Van Bockstaele, F. (2021). Comparison of the chemical and technological characteristics of wholemeal flours obtained from amaranth (Amaranthus sp.), quinoa (Chenopodium quinoa) and buckwheat (Fagopyrum sp.) seeds. Foods, 10(3): 651. https://doi.org.10.3390/foods10030651.

Demir, B. and Bilgiçli, N. (2021). Utilization of quinoa flour (Chenopodium quinoa Willd.) in gluten-free pasta formulation: effects on nutritional and sensory properties. Food Science and Technology International, 27(3): 242-250. https://doi.org.10.1177/1082013220940092.

Di Cairano, M., Condelli, N., Caruso, M.C., Marti, A., Cela, N., and Galgano, F. (2020). Functional properties and predicted glycemic index of gluten free cereal, pseudocereal and legume flours. $L W T$ Food Science and Technology, 133: 109860. https://doi.org/10.1016/j.lwt.2020.109860.

Di Fabio, A. and Parraga, G. (2017). Origin, production and utilization of pseudocereals, In: Haros, C.M. and Schoenlechner, R. (Eds.), Pseudocereals, chemistry and technology. Wiley-Blackwell, pp. 1-27.

Espinosa-Ramírez, J., Rodríguez, A., De la Rosa-Millán, J., Heredia-Olea, E., Pérez-Carrillo, E., and SernaSaldivar, S.O. (2021). Shear-induced enhancement of technofunctional properties of whole grain flours through extrusion. Food Hydrocolloids, 111: 106400. https://doi.org/10.1016/j.foodhyd.2020.106400. 
FAO (2013). Food outlook: Biannual report on global food markets. Rome: Food and Agriculture Organization of the United Nations. Available at: www.fao.org/3/i3473e/i3473e.pdf.

Fernández-López, J., Lucas-González, R., Viuda-Martos, M., Sayas-Barberá, E., Ballester-Sánchez, J., Haros, C.M., Martínez-Mayoral, A., and Pérez-Álvarez, J.A. (2020). Chemical and technological properties of bologna-type sausages with added black quinoa wet-milling coproducts as binder replacer. Food Chemistry, 310: 125936. https://doi.org/10.1016/j.foodchem.2019.125936.

Fuentes, C., Perez-Rea, D., Bergenståhl, B., Carballo, S., Sjöö, M., and Nilsson, L. (2019). Physicochemical and structural properties of starch from five Andean crops grown in Bolivia. International Journal of Biological Macromolecules, 125: 829-838. https://doi.org/10.1016/j.ijbiomac.2018.12.120.

Gallego, D., Russo, L., Kerbab, K., Landi, M., and Rastrelli, L. (2014). Chemical and nutritional characterization of Chenopodium pallidicaule (cañihua) and Chenopodium quinoa (quinoa) seeds. Emirates Journal of Food and Agriculture, 26(7): 609-615.

Gordillo-Bastidas, E., Díaz-Rizzolo, D.A., Roura, E., Massanés, T., and Gomis, R. (2016). Quinoa (Chenopodium quinoa Willd), from nutritional value to potential health benefits: an integrative review. Journal of Nutrition \& Food Sciences, 6(3): 1000497. https://doi.org.10.4172/2155-9600.1000497.

Gupta, A., Sharma, S., and Reddy Surasani, V.K. (2021). Quinoa protein isolate supplemented pasta: nutritional, physical, textural and morphological characterization. LWT - Food Science and Technology, 135: 110045. https://doi.org.10.1016/j.lwt.2020.110045.

Haros, C.M. and Sanz-Penella, J.M. (2017). Food uses of whole pseudocereals, In: Haros, C.M. and Schoenlechner, R. (Eds.), Pseudocereals, chemistry and technology. Wiley-Blackwell, pp. 163-192.

Hinojosa, L., Leguizamo, A., Carpio, C., Muñoz, D., Mestanza, C., Ochoa, J., Castillo, C., Murillo, A., Villacréz, E., Monar, C., Pichazaca, N., and Murphy, K. (2021). Quinoa in Ecuador: recent advances under global expansion. Plants, 10(2): 298. https://doi.org/10.3390/plants10020298.

Houben, A., Götz, H., Mitzscherling, M., and Becker, T. (2010). Modification of the rheological behavior of amaranth (Amaranthus hypochondriacus) dough. Journal of Cereal Science, 51: 350-356. https://doi.org. 10.1016/j.jcs.2010.02.003.

Jan, K.N., Panesar, P.S., and Singh, S. (2018). Optimization of antioxidant activity, textural and sensory characteristics of gluten-free cookies made from whole Indian quinoa flour. LWT - Food Science and Technology, 93: 573-582, https://doi.org/10.1016/j.lwt.2018.04.013.

Janssen, F., Pauly, A., Rombouts, I., Jansens, K.J.A., Deleu, L.J., and Delcour, J.A. (2017). Proteins of amaranth (Amaranthus spp.), buckwheat (Fagopyrum spp.), and quinoa (Chenopodium spp.): a food science and technology perspective. Comprehensive Reviews in the Food Science and Food Safety, 16(1): 39-58. https://doi.org/10.1111/1541-4337.12240.

Jing, R., Li, H.Q., Hu, C.L., Jiang, Y.P., Qin, L.P., and Zheng, C.J. (2016). Phytochemical and pharmacological profiles of three Fagopyrum buckwheats. International Journal of Molecular Science, 17(4): 589. https://doi.org.10.3390/ijms17040589.

Karimian, J., Abedi, S., Shirinbakhshmasoleh, M., Moodi, F., Moodi, V., and Ghavami, A. (2021). The effects of quinoa seed supplementation on cardiovascular risk factors: a systematic review and metaanalysis of controlled clinical trials. Phytotherapy Research, 35(4): 1688-1696. https://doi.org.10.1002/ ptr.6901.

Kreft, S. and Kreft, M. (2000). Localization and morphology of the buckwheat embryo. Fagopyrum, 17: 1519.

Kringel, D.H., El Halal, S.L.M., Zavareze, E.d.R., and Dias, A.R.G. (2020). Methods for the extraction of roots, tubers, pulses, pseudocereals, and other unconventional starches sources: a review. Starch Stärke, 72(11-12): 1900234. https://doi.org/10.1002/star.201900234. 
Kuktaite, R., Repo-Carrasco-Valencia, R., de Mendoza, C.C., Plivelic, T.S., Hall, S., and Johansson, E. (2021). Innovatively processed quinoa (Chenopodium quinoa Willd.) food: chemistry, structure and end-use characteristics. Journal of the Science of Food and Agriculture. https://doi.org/10.1002/jsfa. 11214 (Epub ahead of print).

Kurek, M.A. and Krzemińska, A. (2020). Effect of modified atmosphere packaging on quality of bread with amaranth flour addition. Food Science and Technology International, 26(1): 44-52. https://doi.org.10. $1177 / 1082013219864197$.

Lamothe, L.M., Srichuwong, S., Reuhs, B.L., and Hamaker, B.R. (2015). Quinoa (Chenopodium quinoa W.) and amaranth (Amaranthus caudatus L.) provide dietary fibres high in pectic substances and xyloglucans. Food Chemistry, 167: 490-496. https://doi.org.10.1016/j.foodchem.2014.07.022.

Li, J., Cui, X., Ma, X., Li, C., and Wang, Z. (2019). Recombinant buckwheat trypsin inhibitor improves the protein and mitochondria homeostasis in Caenorhabditis elegans model of aging and age-related disease. Gerontology, 65(5): 513-523. https://doi.org.10.1159/000500156.

Liu, S., Chen, D., and Xu, J. (2019). Characterization of amaranth and bean flour blends and the impact on quality of gluten-free breads. Journal of Food Measurement and Characterization, 13(2): 1440-1450. https://doi.org.10.1007/s11694-019-00060-4.

Lorusso, A., Coda, R., Montemurro, M., and Rizzello, C.G. (2018). Use of selected lactic acid bacteria and quinoa flour for manufacturing novel yogurt-like beverages. Foods, 7(4): 51. https://doi.org.10.3390/ foods7040051.

Ludena Urquizo, F.E., García Torres, S.M., Tolonen, T., Jaakkola, M., Pena-Niebuhr, M.G., von Wright, A., Repo-Carrasco-Valencia, R., Korhonen, H., and Plumed-Ferrer, C. (2017). Development of a fermented quinoa-based beverage. Food Science \& Nutrition, 5(3): 602-608. https://doi.org/10.1002/fsn3.436.

Manassero, C.A., Añón, M.C., and Speroni, F. (2020). Development of a high protein beverage based on amaranth. Plant Foods for Human Nutrition, 75(4): 599-607. https://doi.org.10.1007/s11130-02000853-9.

Martinez-Lopez, A., Millan-Linares, M.C., Rodriguez-Martin, N.M., Millan, F., and Montserrat-de la Paz, S. (2020). Nutraceutical value of kiwicha (Amaranthus caudatus L.). Journal of Functional Foods, 65: 103735. https://doi.org/10.1016/j.jff.2019.103735.

Martínez-Villaluenga, C., Peñas, E. and Hernández-Ledesma, B. (2020). Pseudocereal grains: nutritional value, health benefits and current applications for the development of gluten-free foods. Food and Chemical Toxicology, 137: 111178. https://doi.org.10.1016/j.fct.2020.111178.

Moroni, A.V., Bello, F.D., Zannini, E., and Arendt, E.K. (2011). Impact of sourdough on buckwheat flour, batter and bread: biochemical, rheological and textural insights. Journal of Cereal Science, 54(2): 195202. https://doi.org.10.1016/j.jcs.2011.04.008.

Moscoso-Mujica, G., Zavaleta, A., Mujica, A., Santos, M., and Calixto, R. (2017). Fraccionamiento y caracterización electroforética de las proteínas de la semilla de kañihua (Chenopodium pallidicaule Aellen). Revista Chilena de Nutrición, 44(2): 144-152.

Murakami, T., Yutani, A., Yamano, T., Iyota, H., and Konishi, Y. (2014). Effects of popping on nutrient contents of amaranth seed. Plant Foods for Human Nutrition, 69(1): 25-29. https://doi.org.10.1007/ s11130-013-0392-7.

Niro, S., D'Agostino, A., Fratianni, A., Cinquanta, L., and Panfili, G. (2019). Gluten-free alternative grains: nutritional evaluation and bioactive compounds. Foods, 8(6): 208. https://doi.org.10.3390/ foods8060208.

Penarrieta, J.M., Alvarado, J.A., Akesson, B., and Bergenstahl, B. (2008). Total antioxidant capacity and content of flavonoids and other phenolic compounds in canihua (Chenopodium pallidicaule): an 
Andean pseudocereal. Molecular Nutrition \& Food Research, 52(6): 708-717. https://doi.org.10.1002/ mnfr.200700189.

Pereira, E., Cadavez, V., Barros, L., Encina-Zelada, C., Stojković, D., Sokovic, M., Calhelha, R.C., GonzalesBarron, U., and Ferreira, I.C.F.R. (2020). Chenopodium quinoa Willd. (quinoa) grains: a good source of phenolic compounds. Food Research International, 137: 109574. https://doi.org/10.1016/j.foodres.2020. 109574.

Pereira, E., Encina-Zelada, C., Barros, L., Gonzales-Barron, U., Cadavez, V., and C.F.R. Ferreira, I. (2019). Chemical and nutritional characterization of Chenopodium quinoa Willd (quinoa) grains: a good alternative to nutritious food. Food Chemistry, 280: 110-114. https://doi.org/10.1016/j.foodchem.2018. 12.068 .

Petrova, P. and Petrov, K. (2020). Lactic acid fermentation of cereals and pseudocereals: ancient nutritional biotechnologies with modern applications. Nutrients, 12(4): 1118. https://doi.org.10.3390/nu12041118.

Quiroga Ledezma, C. (2015). Traditional processes and technological innovations in quinoa harvesting, processing and industrialization. In: Bazile, D., Bertero, D., and Nieto, C. (Eds.), State of the art report on quinoa around the world in 2013: Food and Agriculture Organization of the United Nations (FAO) \& Centre de Coopération Internationale en Recherche Agronomique pour le Développement (CIRAD), pp. 218-249.

Ramos Diaz, J.M., Kirjoranta, S., Tenitz, S., Penttilä, P., Serimaa, R., Lampi, A.M., and Jouppila, K. (2013). Use of amaranth, quinoa and kañiwa in extruded corn-based snacks. Journal of Cereal Science, 58(1): 59-67. https://doi.org/10.1016/j.jcs.2013.04.003.

Ramos Diaz, J.M., Sundarrajan, L., Kariluoto, S., Lampi, A.-M., Tenitz, S., and Jouppila, K. (2017). Effect of extrusion cooking on physical properties and chemical composition of corn-based snacks containing amaranth and quinoa: application of partial least squares regression. Journal of Food Process Engineering, 40(1): e12320. https://doi.org/10.1111/jfpe.12320.

Ranilla, L.G., Apostolidis, E., Genovese, M.I., Lajolo, F.M., and Shetty, K. (2009). Evaluation of indigenous grains from the Peruvian Andean region for antidiabetes and antihypertension potential using in vitro methods. Journal of Medicinal Food, 12(4): 704-713. https://doi.org.10.1089/jmf.2008.0122.

Reguera, M. and Haros, C.M. (2017). Structure and composition of kernels: chemistry and technology, In: Haros, C.M. and Schoenlechner, R. (Eds.), Pseudocereals, chemistry and technology. Wiley-Blackwell, pp. $28-48$.

Repo-Carrasco, R., Espinoza, C., and Jacobsen, S.E. (2003). Nutritional value and use of the Andean crops quinoa (Chenopodium quinoa) and kañiwa (Chenopodium pallidicaule). Food Reviews International, 19(1-2): 179-189. https://doi.org.10.1081/FRI-120018884.

Repo-Carrasco-Valencia, R. and Arana, J.V. (2017). Carbohydrates of kernels. In: Haros, C.M. and Schoenlechner, R. (Eds.), Pseudocereals, chemistry and technology. Wiley-Blackwell, pp. 49-70.

Repo-Carrasco-Valencia, R.A., Encina, C.R., Binaghi, M.J., Greco, C.B., and Ronayne de Ferrer, P.A. (2010). Effects of roasting and boiling of quinoa, kiwicha and kaniwa on composition and availability of minerals in vitro. Journal of the Science of Food and Agriculture, 90(12): 2068-2073. https://doi.org.10. 1002/jsfa.4053.

Rocchetti, G., Miragoli, F., Zacconi, C., Lucini, L., and Rebecchi, A. (2019). Impact of cooking and fermentation by lactic acid bacteria on phenolic profile of quinoa and buckwheat seeds. Food Research International, 119: 886-894. https://doi.org/10.1016/j.foodres.2018.10.073.

Rosell, C., Cortez, G., and Repo-Carrasco-Valencia, R. (2009). Breadmaking use of Andean crops quinoa, kaniwa, kiwicha, and tarwi. Cereal Chemistry, 86(4): 386-392. 
Rudra, S.G., Anand, V., Kaur, C., Bhooshan, N., and Bhardwaj, R. (2020). Hydrothermal treatment to improve processing characteristics of flour for gluten-free pasta. Starch - Stärke, 72(9-10): 1900320. https://doi.org/10.1002/star.201900320.

Salas-Valero, L.M., Tapia-Blácido, D.R., and Menegalli, F.C. (2015). Biofilms based on canihua flour (Chenopodium pallidicaule): design and characterization. Quimica Nova, 38(1): 14-21. https://doi.org. 10.5935/0100-4042.20140275.

Schoenlechner, R., Drausinger, J., Ottenschlaeger, V., Jurackova, K., and Berghofer, E. (2010). Functional properties of gluten-free pasta produced from amaranth, quinoa and buckwheat. Plant Foods for Human Nutrition, 65(4): 339-349. https://doi.org.10.1007/s11130-010-0194-0.

Sciarini, L.S., Steffolani, M.E., Fernández, A., Paesani, C., and Pérez, G.T. (2020). Gluten-free breadmaking affected by the particle size and chemical composition of quinoa and buckwheat flour fractions. Food Science and Technology International, 26(4): 321-332. https://doi.org.10.1177/1082013219894109.

Singh, M. and Liu, S.X. (2021). Evaluation of amaranth flour processing for noodle making. Journal of Food Processing and Preservation, 45(4): e15270. https://doi.org.10.1111/jfpp.15270.

Sluková, M., Levková, J., Michalcová, A., Horáčková, Š., and Skřivan, P. (2017). Effect of the dough mixing process on the quality of wheat and buckwheat proteins. Czech Journal of Food Sciences, 35(6): 522-531. https://doi.org.10.17221/220/2017-CJFS.

Srichuwong, S., Curti, D., Austin, S., King, R., Lamothe, L., and Gloria-Hernandez, H. (2017). Physicochemical properties and starch digestibility of whole grain sorghums, millet, quinoa and amaranth flours, as affected by starch and non-starch constituents. Food Chemistry, 233: 1-10. https://doi.org.10. 1016/j.foodchem.2017.04.019.

Srichuwong, S. and Jane, J.-L. (2007). Physicochemical properties of starch affected by molecular composition and structure: a review. Food Science and Biotechnology, 16: 663-674.

Steffolani, M.E., León, A.E., and Pérez, G.T. (2013). Study of the physicochemical and functional characterization of quinoa and kañiwa starches. Starch - Stärke, 65(11-12): 976-983. https://doi.org.10. 1002/star.201200286.

Torbica, A., Hadnađev, M., and Dapčević, T. (2010). Rheological, textural and sensory properties of glutenfree bread formulations based on rice and buckwheat flour. Food Hydrocolloids, 24(6): 626-632. https:// doi.org/10.1016/j.foodhyd.2010.03.004.

Vega-Galvez, A., Miranda, M., Vergara, J., Uribe, E., Puente, L., and Martinez, E.A. (2010). Nutrition facts and functional potential of quinoa (Chenopodium quinoa Willd.), an ancient Andean grain: a review. Journal of the Science of Food and Agriculture, 90(15): 2541-2547. https://doi.org.10.1002/jsfa.4158.

Villacres, E., Pastor, G., Zambrano, I., and Morales, S. (2013). Determinación del perfil de acidos grasos de los granos Andinos sometidos a diferentes condiciones de procesamiento. En Memoria IV Congreso Mundial de la Quinua, Ibarra, Ecuador, 8-12 July.

Wang, X., Lao, X., Bao, Y., Guan, X., and Li, C. (2021). Effect of whole quinoa flour substitution on the texture and in vitro starch digestibility of wheat bread. Food Hydrocolloids, 119: 106840. https://doi.org. 10.1016/j.foodhyd.2021.106840.

Wang, X., Ullah, N., Sun, X., Guo, Y., Chen, L., Li, Z., and Feng, X. (2017). Development and characterization of bacterial cellulose reinforced biocomposite films based on protein from buckwheat distiller's dried grains. International Journal of Biological Macromolecules, 96: 353-360. https://doi.org/10. 1016/j.ijbiomac.2016.11.106.

Zannini, E., Jeske, S., Lynch, K.M., and Arendt, E.K. (2018). Development of novel quinoa-based yoghurt fermented with dextran producer Weissella cibaria MG1. International Journal of Food Microbiology, 268: 19-26. https://doi.org/10.1016/j.ijfoodmicro.2018.01.001. 
Zhu, F. (2016). Buckwheat starch: structures, properties, and applications. Trends in Food Science \& Technology, 49: 121-135. https://doi.org/10.1016/j.tifs.2015.12.002.

Zhu, F. (2021). Buckwheat proteins and peptides: biological functions and food applications. Trends in Food Science \& Technology, 110: 155-167. https://doi.org/10.1016/j.tifs.2021.01.081.

Open Access. This is an open-access article distributed under the terms of the Creative Commons Attribution-NonCommercial 4.0 International License (https://creativecommons.org/licenses/by-nc/4.0/), which permits unrestricted use, distribution, and reproduction in any medium for non-commercial purposes, provided the original author and source are credited, a link to the CC License is provided, and changes - if any - are indicated. 